\title{
ESP Students; Variations across Gender and Proficiency. A Case study
}

MSc. Juliana Çyfeku

\author{
Faculty of Education and Philology, English Language Department \\ University of Korca, Albania \\ juliana.cyfeku@gmail.com
}

\section{Doi:10.5901/jesr.2013.v3n7p774}

\begin{abstract}
This study was conducted to examine certain disturbing issues concerning learning English for Specific Purposes, as a compulsory academic subject at all majors. The subject of the present study were the 57 freshman students (Female $=40$ and Male = 17); at "F.S.Noli" University, History - Geography Department, in Korca, Albania. This study sought to establish what the students were like at the start of their English language course, investigating their strengths and weaknesses. The research questions it addressed are: 1) Are there any variations concerning both genders or within each gendered group? 2) What are the actual proficiency skills Male and Female students employ in English language learning? The scope of this study was to seek and find information relating to both TSA (Target situation analysis) and PSA (Present situation analysis) for a good start in the present ESP course in this department. The whole study developed under the implementation of the two research instruments: Placement test associated with the researcher's accurate Needs analysis. Based on the reliable data the present study concluded that: different proficient students had different language needs. Thus what they were taught, should be restricted to what they need as part of the ESP academic needs. Consequently, once their needs were identified, and most of the gendered variations were specified; the practice educator could easily design the content of the present ESP course for a successful combination of TSA and PSA.
\end{abstract}

Keywords: ESP, gender, variations, proficiency, needs analysis

\section{Introduction}

\subsection{The scope of the research study}

The purpose of the present study was to describe the variations in overall English language learning at the individual item level, by the students as resulted to be in various proficiency levels, in the specific setting of "F.S.Noli " Korça University, History- Geography Department. The central focus was the gender gap that existed among male and female university students in EFL. Since each learner possesses specific skills in foreign language learning, various results yield in the field of foreign language acquisition. Many researchers have dealt with this problem in various educational contexts at different course levels. They have attempted to give possible solutions in reducing at the lowest possible level the gender variations in $\mathrm{L}_{2}$ mastery. Being biologically, mentally and physically different, variations will always consist and be a continuous part of our teaching experience in foreign language learning. Thus, all kinds of English educators should focus on the actual learner's proficiency level to develop accurate course designs that would assist learners despite their genetic variations to surpass their current level of EFL proficiency into a more advanced EFL level. In addition, the implementation of standard diagnostic tools will yield in precise outcomes to elaborate our teaching process in diminishing to the maximum the variations across gender and proficiency that may exist or occur alongside the process of English language learning. So for a more detailed view of the above mentioned issues in EFL learning the research questions that the present study addressed are: 1) Are there any variations concerning both genders or within each gendered group? 2) What the actual proficiency skills Male and Female students employ in English language learning?

Since English language is part of various ESP academic programs, it demands practice educators to foster the learners a strong motivation for a good start in L2 mastery. Richards (2001) defines English for Specific Purposes as "the role of English in a language course or program of instruction in which the content and aims of the course are fixed by specific needs of a particular group of learners". Whereas, Boom-long (1999) defines that English for Specific Purposes is an approach to language learning, which is based on the learner's needs. Accordingly, all decisions in relation to the content and method are based on the learner's reasons for learning. Moreover, there is a close correlation between ESP and needs analysis. Dudley-Evans (2004) inferred in the statement that "The key defining feature of ESP is that its 
teaching and materials are founded on the results of needs analysis." Principally, it demands planning available course design tasks to assist and provide them alongside this complex process with sufficient language facility to respond to various incoming professional situations. To serve this purpose, it is worth referring to what Jordan (1997) proposes "deficiency analyses", which is concerned with the necessities that the learner lacks. Thus being part of needs analyses, we should employ specific approaches to verify what Robinson (1991) defines as "Present situation analysis " (PSA) versus " Target situation analysis " (TSA). Considering these terms, the present study aimed at finding out the students' English proficiency level since the beginning of the language course. In addition to their existing English language requirements, they were assessed with the requirements of the demanding target situation.

Data from the submission of the Placement test (Diagnostic test), reported the students to be at different proficiency levels. Moreover, the most striking feature was the gender variations elicited from the gendered comparative outcomes among the present freshman English learners. It is important to emphasize the fact that in general they may be successful learners in other subjects except for English. This study addressed the fact that at the time of this study they had not been successful learners of English for some possible reasons. The fact that many students do not become fluent in English despite years of English classes and the place, where they came from, has become a crucial question in a range of studies that seeks an immediate and proper answer to assist both students and teachers in foreign language acquisition. Among the factors that are almost certainly involved in EFL, are the variations in the quality of English instructions students receive and the cultural resistance toward the English language examined in various research studies of (Bliss, 1993; Resnick et al., 1993). Professionally speaking, I agree that the above mentioned factors have a pervasive influence in EFL learning. Besides, another important factor to be focused on is gender, which may be seen as a predictable factor in EFL / ESL learning and acquisition that practice educators encounter among university students. Taking into consideration all the overstated factors, the scope of the present study was to examine gender by making comparisons and observations to elicit the possible and influential variations in the English mastery by university students at all levels.

\subsection{Overall views concerning gender variations in English foreign language learning.}

Gender has been a troublesome issue and the central focus in various researches in EFL / ESL learning and acquisition. Gender is such a complex issue and is seen in various relationships from researchers to find out the influence it has or not in EFL / ESL proficiency at any student level (elementary, secondary, university and tertiary). The most striking fact is that numerous populist explanations (biological and socio-cultural) have been offered for the proposed gender variations in EFL. Recent populist explanations often draw on biological theories the emphasis that gender differences, in favor of females, are rooted in differential brain wiring, maturation rates, and chemistry of boys (Gilbert \& Muspret, 2002).

Specifically, gender was investigated as a mainstream issue relatively late in the sociology of education. Genetic explanations of gender differences in achievement were influential in psychology during the 1970's, even though the biological determinist approach has a long history. The crucial belief of biological theorists is that gender differences are natural and therefore unalterable. Educationally, then, it would be right to treat female and male students differently in any proficiency level, because their natural inclination are towards different adult roles. As a result various theories stated firmly that females excelled at language base subjects and provided greater verbal and reasoning abilities. On contrary, they were under-estimated in Mathematics and science-based subjects because of their lower levels of innate spatial ability, which restricted their understanding of shape and form (GCSE reports). Concern about gender and general educational proficiency should focus mainly on the extent to which female and male students perform differently in different subjects and explain possible factors of their tendency to yield to gendered gaps in the educational process.

Moreover, the theories of left - and right - brain functioning have led to continuous research on the biological differences in brain lateralization. Brown (1994) states that the left hemisphere is associated with logical and critical thought, analyzing every single information, whereas the right hemisphere is more efficient in processing visual and emotional information. Brown (1994) also refers to research by Krashen and Selinger who agree that left-brain dominant learners prefer to be equipped with a rule that they can constantly apply in language use, whereas right-brain dominant learners prefer to discover the rules for themselves to see the way authentic language behaves in various contexts. In addition to the above assumptions, Oxford (1994) reports that females tend to favor subjectivity and emotional responses when learning a new language. Whereas males prefer objectivity: working from rules, evidence and logic.

Besides, nowadays science has shown that females have more connections with their brain hemispheres, which help them to multitask better. Males, on the other side, have a better ability to singularly focus. This means that long term projects or long classrooms tasks should be broken by the teachers into specific tasks to accommodate both 
genders. According to gendered brain theory, the connectors in the female brain also allow girls to process language faster. This theory explores the current research on the developmental, functional and structural similarities and differences in the male and female brains.

Consequently, considering all the stated facts and assumptions put forward by a wide range of researches as investigative issues in the educational process, the practice and innovative educators should investigate the obvious variations they encounter as incentives to their teaching practices. They are given the opportunity to seek and analyze themselves such variations in foreign language acquisition and find approaches of presenting language in a way that enhances each student's worth and meaning.

\section{Methodology}

\subsection{Participants}

The present study was administered to the freshman students of "F.S.Noli" University, History-Geography Department. A total of 57 students participated in the study. There were respectively $\mathrm{N}=40$ Females and $\mathrm{N}=17 \mathrm{Males}$. Their average age varied from 19-21. The Placement test was conducted at the beginning of the study to define their level of comprehension in English. The test results evaluated on the reliable basis according to the Common European Framework for Adult Courses reported them to be at $\mathrm{B}_{1}$ level. The students were grouped under two levels of proficiency: Pre-intermediate and Intermediate.

\subsection{Instruments and procedure}

\section{*Placement Test *Needs analyses}

The Placement Test was conducted to the students since the beginning of the English courses of the academic year 2012-2013. Students were explained at first the scope of applying it among them. English is a compulsory subject in Albanian schools from third grade to high school. So all of these students, regardless of course level, had been exposed to a considerable amount of English instruction. Since they came from different schools, urban or rural ones, from different areas they assessed English language skills at a range of levels. Throughout this test areas of deep comprehension were defined in terms of vocabulary, grammar and writing. It provided accurate assessments of each language skill at the appropriate level that revealed the actual participants' level in English. There exist a wide range of placement tests designed for English learners to examine the learner's general basic ability in English. They are designed around for essential qualities: validity, reliability, impact and practicality. They produce exact scores of the learner's true level of language skills. The conducted Placement Test was designed from LSI (Language Studies International, Kreuzstasse 36,8008 Zurich).

The test included two parts : 1) 50 multiple choice questions (each with $a, b, c$, d alternatives), concerning grammar aspects and vocabulary 2) English writing test limited to 100 words writing about the students' current language learning goals. Getting the exact participants' results the researcher obtained a view that reflected the current level of each English learner's proficiency. A careful needs analysis was carried out for this course. The students were found to possess typical gender differences in the degree of the English language proficiency. The test examined the level of comprehension of the most important grammar aspects for the present ESP learners. It included mostly English language specifications such as understanding of the structure of the language used, understanding of grammatical notions of relative time, space, possession, supposition, collocations, verb patterns and phrasal verbs. Concerning the writing section it tested the way they gave information on the given topic related to their English language experience. It fostered their current language goals of learning at university level by using appropriate vocabulary to express each participant's emotions, attitudes, reactions toward English as an international foreign language. The limited time to complete the test was 60 minutes. A standardized score was set to evaluate the whole test scores on a fixed scale out of 70. Based on Bloom's Taxonomy which involves six thinking levels (Cognition, Understanding, Application, Analyses, Synthesis, Evaluation), students were marked with the exact grades and were divided into two proficiency groups to serve the purpose of the present study.

\section{Results and findings}

The outcomes of the Placement Test reported significant variances among the freshman university students. The test 
provided placement results for each individual in EFL proficiency. It checked the wide areas of English language comprehension including vocabulary and grammatical knowledge in Part I, whereas in Part II it tested the students' writing ability regarded as a linguistic, cognitive, social and cultural phenomenon closely related to the English language. The writing task demanded structural, logical and critical thinking from the students' part. Additionally, they were required to focus on different aspects of their knowledge experience in EFL to produce a solid and precise written performance for a straightforward evaluation. On purpose, Bloom's Taxonomy of evaluation was applied in the present study to investigate thoroughly the students' proficiency in the following group divisions. Bloom's Taxonomy is used in all kinds of tests to yield to accurate, reliable, valid final results. The criterion it comprises enhances appropriate viewpoints to the practice educators for each participant student involved in it. The table below shows the way of grading the students based on Bloom's Taxonomy of evaluation.

Table 1. Bloom's Taxonomy of evaluation

\begin{tabular}{|c|c|c|c|c|c|c|c|}
\hline Grade & $\mathbf{4}$ & $\mathbf{5}$ & $\mathbf{6}$ & $\mathbf{7}$ & $\mathbf{8}$ & $\mathbf{9}$ & $\mathbf{1 0}$ \\
\hline Interval & $0-24 \%$ & $25-38 \%$ & $39-51 \%$ & $65-77 \%$ & $78-90 \%$ & $78-90 \%$ & $91-100 \%$ \\
\hline Points & $0-17$ & $18-27$ & $28-36$ & $37-45$ & $46-54$ & $55-63$ & $64-70$ \\
\hline
\end{tabular}

The proper grade for each student's score was presented as below:

Table2. Grading scale

\begin{tabular}{|c|c|c|c|}
\hline Remarks & Grade & Points & Percentage \\
\hline Magnificant & 10 & $64-70$ & $91-100 \%$ \\
\hline Excellent & 9 & $55-63$ & $78-90 \%$ \\
\hline Very good & 8 & $46-54$ & $65-77 \%$ \\
\hline Good & 7 & $37-45$ & $52-64 \%$ \\
\hline Satisfactory & 6 & $28-36$ & $39-51 \%$ \\
\hline Pass & 5 & $18-27$ & $25-38 \%$ \\
\hline Fail & 4 & $0-17$ & $0-24 \%$ \\
\hline
\end{tabular}

The subjects of the study were divided into two controlled groups of proficiency to make comparisons, test the research questions and draw conclusions on the demanded needs analysis. Thus, students getting 18 - 45 out of 70 were enrolled in Pre-intermediate controlled group, whereas the remaining part getting 46 - 70 out of 70 were enrolled in Intermediate controlled group of the present study. The conducted preliminary English test provided them with a straightforward frame of what their current English level was indeed. Moreover, goals were set throughout the researcher's needs analysis, to achieve obvious leaps of advancement at the end of the English academic program. Evidently, the students were aware of the wide range of skills they had to develop during the EFL process since the starting point of the present study, to make practical use of English in a variety of contexts.

The Placement test assessed language skills at a range of levels and provided accurate evaluations of each student's current knowledge of EF language structure and use. It suited to the teaching curriculum regardless their specific exposure to English instructions attained in the secondary education. It endeavored to be fair to all of them, whatever their regional and linguistic background, gender or disability features they claimed to be part of. The scores it produced provided an accurate reflection of each student's true level of English language skills. The reliability of the final results relies on the fact that they were stable, consistent and accurate to draw specific conclusions on what each student was expected to use in English. For a precise view, consider the following results.

Table 3. Placement test results

\begin{tabular}{|c|c|c|c|c|c|}
\hline English language skills & Grades & \multicolumn{2}{|c|}{ Female - \% } & \multicolumn{2}{|c|}{ Male - \% } \\
\hline Magnificant & 10 & - & - & - & - \\
\hline Excellent & 9 & 2 & $5 \%$ & - & - \\
\hline Very good & 8 & 5 & $12 \%$ & 2 & $12 \%$ \\
\hline Good & 7 & 17 & $43 \%$ & 3 & $18 \%$ \\
\hline Satisfactory & 6 & 16 & $40 \%$ & 5 & $29 \%$ \\
\hline
\end{tabular}




\begin{tabular}{|c|c|c|c|c|c|}
\hline Pass & 5 & - & - & 3 & $18 \%$ \\
\hline Fail & 4 & - & - & 4 & $23 \%$ \\
\hline Total & & 40 & $100 \%$ & 17 & $100 \%$ \\
\hline
\end{tabular}

The division of all students into two proficiency levels is considered as an accurate criterion to award each student with a global mark (see Table. 3) and investigate the linguistic variations that existed between both genders. Thus, as (Table. 4) displays students getting 18 - 45 out of 70 were estimated as Pre-intermediate students, whereas students getting 46 70 were estimated as Intermediate students.

Table 4. Distribution of students by Course level and Gender

\begin{tabular}{|c|c|c|c|c|}
\hline Course level & Female & Male & Total & Percentage \\
\hline Intermediate & 24 & 4 & 28 & $49 \%$ \\
\hline Pre-Intermediate & 16 & 13 & 29 & $51 \%$ \\
\hline Overall & 40 & 17 & 57 & $100 \%$ \\
\hline
\end{tabular}

\section{Analyses and discussions}

Test results pointed out the differences in male and female involvement in each respective controlled group. Thus based on the reliable data obtained from the Placement test, and as observed from the above tables, the first research question proved that there existed obvious variations in the degree of the investigating variables gender and proficiency. The former was the main investigative focus of conducting the present research study, whereas the latter was considered as a common denominator to assess the learner's language ability test. The striking variations versus gender were the extreme results (see Tb. 3) where females outperformed males in a degree of $5 \%$ as excellent learners when opposed to the average male degree of $41 \%$ who resulted to be mostly moderate English language learners. Furthermore variations were noticed in a considerable \% at the females' advantages in equal proportions half as moderate and half as good learners. Nevertheless, what served as an incentive for a progressive level of both genders was the equal degree of $12 \%$ in reporting them to be very good English language learners at this phase of the research study.

Additionally the variations between males and females demanded the present study to focus on the fact that the overwhelming part of both genders (see Tb.4) pertain to Pre-intermediate level (16 females and 13 males) and to Intermediate level ( 24 females and 4 males). As it can be observed, a considerable part of females $42 \%$ are involved in Intermediate level and $29 \%$ in Pre-intermediate level, thus outperforming males in an amount of $7 \%$ in Intermediate level and $22 \%$ in Pre- intermediate level. It is worth mentioning the fact that both genders were expected to be at $B_{2}$ level. The Placement Test reported them to be at $B_{1}$ level, where females outperformed males in both levels, especially in Intermediate level in an advantage of 24 female students to 4 male students.

Besides defining the controlled groups' variations, the second research questions demanded additional conclusive observations to specify the very specific skills that Male and Female students employed in English language learning. Comparisons were drawn to view the differences that consisted in various areas of the English proficiency such as the tested skills of 1) reading concerning vocabulary \& grammar and 2) writing. Accordingly, based on the above comparisons females resulted to employ most of the skills in English than males did, considered so, on all stages of the present study. Procedurally, they covered mostly the areas of using correctly the proper vocabulary; used precisely the tested grammar aspects when compared to males' evaluation which resulted to be less knowledgeable in the overall areas of the English language comprehension. Precisely, the test results reported females to outperform males in constructing good and meaningful sentences in the writing task. Female's writing consisted of extensive writing in length that was relevant to the topic and maintained a coherent flow of language to achieve meaningful communication with the reader. When compared to females', males' writing was generally vague; moreover $M=6$ or (35\%) out of 17 Male students did not accomplish at all the writing task. Differences consisted in the incorrect use of sentence structure, cohesion, and shallow ideas to serve the purpose of the given topic. For a precise view consider the following report (Table. 5.) on the most specific gender differences of the present research findings. 
Table 5. Evaluation gender report

\begin{tabular}{|c|c|c|c|c|c|c|}
\hline Skills & & Reading & & Writing & & \\
\hline Gender/ Male & Sub skills & $\begin{array}{c}\text { Vocabulary } \\
\text { comprehension }\end{array}$ & $\begin{array}{c}\text { Grammar } \\
\text { comprehension }\end{array}$ & Sub skills & $\begin{array}{c}\text { Vocabulary } \\
\text { use }\end{array}$ & Grammar use \\
\hline Level & Remarks & No. & No. & Remarks & No. & No. \\
\hline Pre-Intermediate & Moderate & 13 & 10 & Moderate & 5 & 8 \\
\hline Intermediate & Good/very good & 4 & 7 & Good/very good & 6 & 3 \\
\hline Total & & 17 & 17 & & 11 & 11 \\
\hline
\end{tabular}

Note * 6 students did not do the writing task.

Table 6. Evaluation gender report

\begin{tabular}{|c|c|c|c|c|c|c|}
\hline Skills & Reading & & Writing & & \\
\hline Genderl Female & Sub skills & $\begin{array}{c}\text { Vocabulary } \\
\text { comprehension }\end{array}$ & $\begin{array}{c}\text { Grammar } \\
\text { comprehension }\end{array}$ & Sub skills & $\begin{array}{c}\text { Vocabulary } \\
\text { use }\end{array}$ & $\begin{array}{c}\text { Grammar } \\
\text { use }\end{array}$ \\
\hline Level & Remarks & No. & No. & Remarks & No. & No. \\
\hline Pre-Intermediate & Moderate & 16 & 28 & Moderate & 19 & 26 \\
\hline Intermediate & $\begin{array}{c}\text { Good/very } \\
\text { good }\end{array}$ & 24 & 12 & $\begin{array}{c}\text { Good/very } \\
\text { good }\end{array}$ & 21 & 14 \\
\hline Total & & 40 & 40 & & 40 & 40 \\
\hline
\end{tabular}

As it is seen from the above results, there existed a vast gap between both genders and within each engendered group. Eventually, analyzing male findings we yield in the conclusion that they had a general level of comprehension concerning vocabulary. Additionally, considering the figures of the tested skills by gender and proficiency we notice male findings were so uneven in the assessments of them. As observed, overwhelmingly (67\%) they pertained to the Pre-Intermediate level only in the mean score of the reading skill. On the other side, they lacked accuracy, comprehensibility for grammatical and lexical planning, a fact which reported so evident in the mal accomplishment of the writing task so making it obvious a great part of them (35\%) positioned as neutral in between levels. Evidently, the variations became more intense when compared with the females' performance in the writing skill. Precisely, view the figures below.

Figures 1\&2: Observations of Skills by Gender and Proficiency

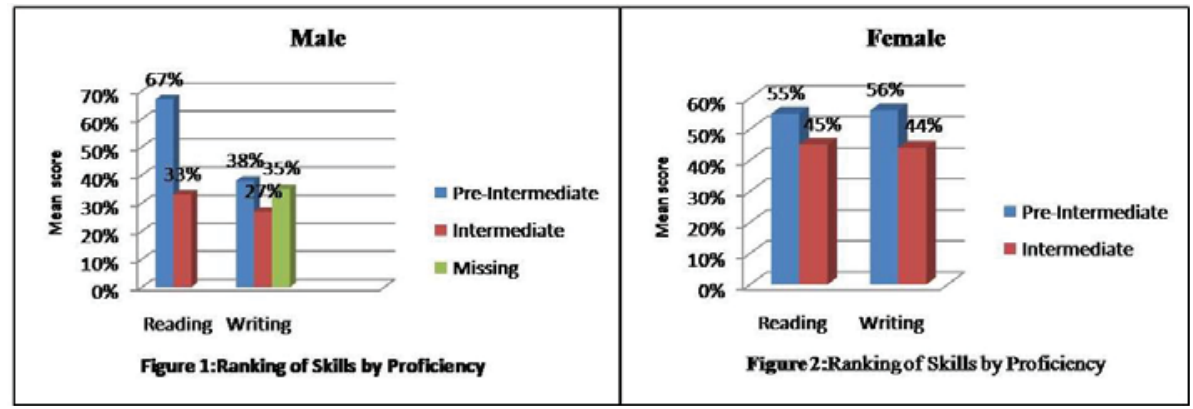

Eventually, female findings reported them to be overwhelmingly good users of English reporting the same degree of comprehension and use of the tested skills with equal proportions and slight variations between Intermediate and Pre Intermediate levels. Moreover, they outperformed males outcomes concerning writing skills in the tested sub skills, grammar comprehension and grammar use. Furthermore, when compared within the gender group, both genders resulted to have specific grammatical gaps that needed to be focused on by the researcher as an important issue of the ESP course needs analysis. In addition, the greatest variations affected from except the variable gender, and observed in the present study were those versus proficiency. Based on the reliable data we come to the conclusion that different proficient students had different language needs and that the more proficient the learners tended to be the lower in degree the variations would be. For this reason, we should take into consideration that variations in EFL or ESP will be part of our teaching process of either male or female freshman university students. Besides their actual learner 
characteristics, studying for only two full terms they need to acquire all the above mentioned components of the English language in addition to the specific lexicon of their professional education. Principally, learning English as a specific language at university level, is a process that is speeded by intensive language courses and is directed through academic study to attain an advanced level of EFL proficiency. That is why overall university or ESP learners should be clear of the fact that adult learning is a relatively conscious process. They need themselves to control their exact level of the English language mastery and individually seek opportunities to speed the overall learning process.

Consequently, the needs analysis involved in the identification and evaluation of the problems that both target genders had in English, ensured success for the present ESP learners. This was done through implementing it before the course, during the course, and at the end of the course. Analyzing thoroughly its outcomes, the stated needs analysis served as a key instrument in the following academic course designs in ESP at all majors to provide practicality, authenticity and professionalism in the teaching process. Following these steps, all kinds of practice educators will no doubt be ready and skillful to create a syllabus which will meet the needs of the learners at the highest possible level within various contexts of applying English for specific professional purposes.

\section{Conclusions}

Students enroll to university English courses to expand their knowledge in it and to accomplish the demands it requires as a compulsory academic subject. Being so, it neglects their gendered variations (either biological or sociological) overstated in the Literature review. Thus the university teachers need to adopt programs to provide further learning experiences to consolidate the student's knowledge, understanding and assessment of skills in EFL. Since they come directly from secondary education, coming from rural or urban areas, they are supposed to have the same level of proficiency. The conducted placement test of this research resulted that males and female were between $\mathrm{B}_{1}$ and $\mathrm{B}_{1}+$ level. Moreover, the results indicated that females prevailed males in the proficiency level. Specifically, females reflected their profound knowledge they exerted in vocabulary, grammar and especially in the writing skills, whereas most of the males did not accomplish the writing task successfully. Despite the fact of being able to carry on a conversation in the target language the findings reported that male students were not totally equipped with the proper skills to deal with academic materials in that language. The evident outcomes of the Placement test were considered as central points to the present needs analysis research that was carefully elaborated and adopted to integrate English language learning and the academic assessments that the ESP students needed to assimilate to.

Moreover, the point of such ESP principles should enhance student's learning experiences. Eventually, interaction in the language is needed for the learner to communicate personal meaning in the target language (Cummins and Swain 1986). Besides language learning, language practice which takes place in relevant context will then result in the acquisition of the language. Language is a tool among others, designed to promote knowledge and make these learners communicatively and professionally competent users of English. For this reason, ESP courses should be considered as a pathway towards success in future specialized studies. Consequently, the courses need to be carefully designed relying on evidence (here; outcomes of the diagnostic test). In other words what our duty necessitates is to implement well designed, effective, efficient and course - based assessments on the actual student's skills, needs and interests in English. Additionally, Holden (1997) in his study, stresses the steps that teachers must take before setting up ESP courses: 1) Learners' language ability test e.g. a Placement test. 2) Setting learners' final target level e.g. by referring to the stages of Attainment Scale. Thus implementing up-to-date research tools in our researches and teaching practices, we yield in the identification and examination of the overstated criteria to any educational institution. Procedurally, they should be a prerequisite for any program or course design in order to achieve effective instructional outcomes in the English language academic learning. Decisively, it is of vital importance to seek and find information relating to both TSA (Target situation analysis) and PSA (Present situation analysis) for a good start in various ESP course settings. To serve the purpose, the ESP teacher or researcher should experiment on students, establish close and constant relations with them and other practitioners as well. Consider the fact that Peacock (2001) experimented on 206 EFL students and 46 EFL teachers at a Hong Kong university to prove Reid's two major hypotheses that "all students have their own learning styles and learning strengths and weaknesses", and "a mismatch between teaching and learning styles causes learning failure and frustration." Thus a continuous observation of the learners' needs can provide reliable and objective data for the practice educators with all the students' specific variations either engendered or individual language learning features and styles when working in ESP programs.

To conclude, respecting the students' specific variations as solid but changeable components under continuous control and instructions; involved in ongoing academic assessments helps the practitioners be reasonable and practical 
to discrepancies between the current ESP curriculum and the students' needs. Finally, what we attain at the end of the teaching process is an overview and a reconsideration of our teaching subjects, the academic curricula in general, syllabus design, the methodological approaches so to enhance effective teaching in academic learning. Following such simple but accurate steps in ESP courses at various majors will for certain yield in more proficient and less gendered outcomes.

\section{References}

Bliss, P.A. (1993, March 9). Emphasis on English. San Juan Star, pp.F8-F9.

Bloom, Benjamin S. Taxonomy of Educational Objectives (1956). Published by Allyn and Bacon, Boston, MA. Copyright (c) 1984 by Pearson Education

Boon-long, V. (1999). English for Specific Purposes: An Introduction. n. p.

Brown,H.D. (1994) Principles of Language Learning and Teaching. Third edition Englewood Cliffs .New Jersey: Prentice Hall.

Cummins, J. \& Swain, M. (1986.) Bilingualism in education. New York; Longman.

Dudley-Evans, T. (2004). English for Specific Purposes. in R.Carter and D.Nunan (Eds.). The Cambridge Guide to Teaching English to Speakers of Other Languages. Cambridge: Cambridge University Press.

GCSE. Retrieved on November 20, 2010 from www.earlhamsociologypages.co.uk/genderand\%20femaleedimprovement.ppt

Gilbert, P., \& Musprett, P. (2002). Readers than boys? Which boys? Which girls?

www.csse-scee.ca/CJE/Articles/FullText/CJE30-2/CJE30-2-White.pdf · PDF file

Holden, S. (1997).English for Specific Purposes. London: Modern English Publications.

Jordan, R. (1997). English for Specific Purposes. Cambridge: CUP.

LSI. Placement Test. Retrieved from http://www.|sizh.ch/documents/standard\%20English20Placement\%20Test.pdf

Oxford , R (1994). Gender differences in second/ foreign language learning styles and strategies. Oxford: Oxford University Press.

Peacock, M. (2001). Match or mismatch? Learning styles and teaching styles in EFL. International Journal of Applied Linguistics, 11 (1): 38-58.

Resnick, M. C (1993). ESL and language planning in Puerto Rico. TESOL Quarterly 27, 259-275.

Richards, J.C. (2001). Curriculum Development in Language Teaching. Cambridge: Cambridge University Press.

Robinson, P. (1991). Needs Analysis. ESP today. Prentice Hall. 